\title{
Pediatric COVID-19 Infection: Do Clinical Features and Hematological Parameters Predict the Need for ICU Admission?
}

\author{
Shaimaa Reda Abdelmaksoud ${ }^{1 *}$, Rana Atef Khashaba ${ }^{2}$, Rasha Shaker Eldesouky ${ }^{3}$, Effat Assar ${ }^{1}$ \\ Departments of ${ }^{1}$ Pediatrics, ${ }^{2}$ Clinical Pathology and Chemistry and \\ ${ }^{3}$ Community Medicine, Benha Faculty of Medicine, Benha University, Egypt.
}

Corresponding author: Shaimaa Reda Abdelmaksoud, Mobile: (+20) 01001814411, E-Mail: shaimaareda82@gmail.com

\begin{abstract}
Background: The world is facing the new pandemic caused by SARS-COV2. The confrontation of this new pandemic necessitates study and analysis of the clinical and laboratory finding in such entity.

Objectives: To discuss the clinical and hematological findings in pediatric patients with SARS-CoV-2 infection and to correlate these characters with the need for ICU admission.

Patients and methods: This was a hospital record-based study, in which the clinical features and laboratory findings of 29 pediatric patients with confirmed COVID-19 infection were obtained from the medical records of admitted pediatric patients.

Results: This study included 29 pediatric patients with confirmed COVID-19 infection. Six cases (20.7\%) were admitted to pediatric ICU. The most common presenting symptoms were cough in 23 cases $(79.3 \%)$ and fever in 19 cases (65.5\%). There was a significant association between tachypnea and ICU admission; as 5 out of 6 ICU cases (83.3\%) had tachypnea compared to none $0 / 23(0.0 \%)$ of the non ICU patients $(\mathrm{P}<0.001)$. The frequencies of lymphopenia and thrombocytopenia were higher among ICU patients (100.0\% and $50.0 \%$ respectively) than the non ICU ones ( $39.1 \%$ and $8.7 \%$ respectively) ( $\mathrm{P}<0.05$ for both). The median values of lymphocytes and platelets counts were significantly lower in ICU patients than those of non ICU patients ( $\mathrm{P}=0.002$ and 0.007 respectively). CRP values were higher in ICU patients compared to non ICU patients $(\mathrm{P}=0.011)$.

Conclusion: Decreased lymphocyte count, thrombocytopenia and elevated CRP can be stood out as discriminative laboratory indices for early ICU admission.

Keywords: Clinical features, Hematological, Lymphopenia, Pediatric COVID-19.

Registry: The study was registered as an observational study at ClinicalTrials.gov ID: NCT04487119.

\section{INTRODUCTION}

In December 2019, a new infectious disease broke out in Wuhan, Hubei Province, China. The cause of this outbreak was a new corona virus called severe acute respiratory syndrome coronavirus 2 (SARSCoV-2), which was accountable for Corona Virus Disease 2019 (COVID-19) ${ }^{(1)}$.

Corona Virus disease 2019 (COVID-19) was more prevalent among adults in the early stages of the outbreak, and the proportion of confirmed cases among children was relatively small. Since then, however, given that younger children cannot wear masks and have not taken other special preventive and control measures, the number of cases of infection in children has increased dramatically, particularly in younger age groups, and therefore great attention should be paid ${ }^{(2)}$.

The novel virus genome and early epidemiological and clinical features of infection in adults have been reported ${ }^{(3,4)}$. It has been estimated that the infection has an incubation period of 5.2 days and usually causes fever, cough, muscle pain, and pneumonia in patients ${ }^{(3)}$.

Xu et al..$^{(5)}$, conducted nucleic acid tests on 745 children and 3174 adults with a history of close contact with COVID-19 patients, they found that $1.3 \%$ and $3.5 \%$ tested positive in children and adults respectively. Body temperature, routine blood tests,

and chest computed tomography tests showed that, compared with adults, children with COVID-19 were less ill and exhibited less obvious symptoms, and were not typical.

Fever and cough are the most common clinical manifestations in children with COVID-19, with some being accompanied by fatigue, muscle pain, nasal congestion, runny nose, sneezing, sore throat, headache, dizziness, vomiting and/or abdominal pain. A small number of children can be presented without a fever, but only a cough or diarrhea is apparent, and even a smaller number can be asymptomatic. Some babies and newborns can develop atypical symptoms, such as vomiting, diarrhea and other digestive symptoms, or only asthma and shortness of breath ${ }^{(6)}$.

Fan et $\boldsymbol{a l} .{ }^{(7)}$, studied the hematologic parameters in adult patients with COVID-19 infection and stated that $29.2 \%$ of patients showed leukopenia and $36.9 \%$ of patients showed lymphopenia. Most patients had normal platelet counts, with $20.0 \%$ having mild thrombocytopenia.

Little is known about the effect of COVID-19 disease on pediatric hematology ${ }^{(8)}$. Furthermore; children exhibit certain particularities and cannot clearly describe their own health status or contact history, which has contributed to the severe challenge of protecting, diagnosing, and treating this population ${ }^{(6)}$.
\end{abstract}


The aim of this study was to discuss the epidemiological, clinical, and hematological features in pediatric patients with SARS-CoV-2 (COVID-19) infection and to correlate these characters with the need for ICU admission.

\section{PATIENTS AND METHODS}

This study was conducted at Benha University Hospital, Benha, Egypt. We included in this hospital records-based study all pediatric patients who were admitted with confirmed COVID-19 infection with age range from birth to 18 years during the period from 25 April 2020 till 10 July 2020. The diagnosis of COVID-19 infection was based on positive SARSCoV-2 RNA detection in throat swab specimens by polymerase chain reaction (PCR).

Patients with records missing hematology and/or laboratory data, transferred to other medical facilities with unknown outcomes, or with age older than 18 years, were excluded from the study.

\section{Data collection:}

All data including demography information, contact history, previous history, clinical symptoms, clinical examination on admission, and hematology and laboratory information on admission were obtained from inpatient medical records.

\section{Ethics and Consent:}

The study was performed in accordance with the Helsinki declaration and its amendments. The study protocol was approved by the Research Ethics Committee at Faculty of Medicine, Benha University (REC-FOMBU), Egypt with approval number RC6.7.2020.

\section{Statistical analysis:}

The collected data were tabulated and analyzed using SPSS version 16 software (SPSS Inc, Chicago, ILL Company). Categorical data were presented as number and percentages; Fisher's exact test was used to analyze them. Quantitative data were tested for normality using Shapiro-Wilks test assuming normality at $\mathrm{P}>0.05$. As proved non-parametric, they were presented as median and interquartile range (IQR), and analyzed by Mann-Whitney U test. Twosided $\mathrm{P} \leq 0.05$ was considered significant.

\section{RESULTS}

This study included 29 pediatric patients with confirmed COVID-19 infection. Patient ages ranged from 45 days to 14 years (Table 1).

Six cases out of $29(20.7 \%)$ were admitted to pediatric ICU. Upon which, the studied patients were classified as non ICU and ICU groups, as shown in table 1. There were no statistically significant differences between the two groups regarding socio-demographic characters.

Table (1): Socio-demographic data among the studied sample.

\begin{tabular}{|c|c|c|c|c|c|c|c|c|}
\hline \multirow{2}{*}{\multicolumn{2}{|c|}{ Variable }} & \multicolumn{2}{|c|}{$\begin{array}{c}\text { Non ICU pediatric } \\
\text { patients }(n=23)\end{array}$} & \multicolumn{2}{|c|}{$\begin{array}{l}\text { ICU pediatric } \\
\text { Patients }(n=6)\end{array}$} & \multirow[t]{2}{*}{$\begin{array}{c}P \text { - } \\
\text { value }\end{array}$} & \multicolumn{2}{|c|}{$\begin{array}{c}\text { Overall patients } \\
(\mathbf{n}=29)\end{array}$} \\
\hline & & $\begin{array}{l}\text { Median } \\
\text { (IQR) }\end{array}$ & No.(\%) & $\begin{array}{l}\text { Median } \\
\text { (IQR) }\end{array}$ & No. $(\%)$ & & $\begin{array}{l}\text { Median } \\
\text { (IQR) }\end{array}$ & No. $(\%)$ \\
\hline \multicolumn{2}{|c|}{ Age (years) } & $5.5(3.5-9.5)$ & & $5(1.5-8)$ & & 0.53 & $5.5(3.25-9.5)$ & \\
\hline \multirow{2}{*}{ Gender } & Male & & $8(34.8)$ & & $4(66.7)$ & \multirow{2}{*}{0.16} & & $12(41.4)$ \\
\hline & Female & & $15(65.2)$ & & $2(33.3)$ & & & 17 (58.6) \\
\hline \multirow{2}{*}{$\begin{array}{l}\text { Contact } \\
\text { History }\end{array}$} & Yes & & $15(65.2)$ & & $5(83.3)$ & \multirow{2}{*}{0.39} & & $20(69.0)$ \\
\hline & No & & $8(34.8)$ & & $1(16.7)$ & & & $9(31.0)$ \\
\hline \multicolumn{2}{|c|}{ Weight (kg) } & $21(14-32)$ & & $20(9.3-31.1)$ & & 0.64 & $21(13.75-31)$ & \\
\hline
\end{tabular}

ICU: intensive care unit; IQR: interquartile ranges. 
Different clinical features of the enrolled COVID-19 patients were displayed in figure 1.

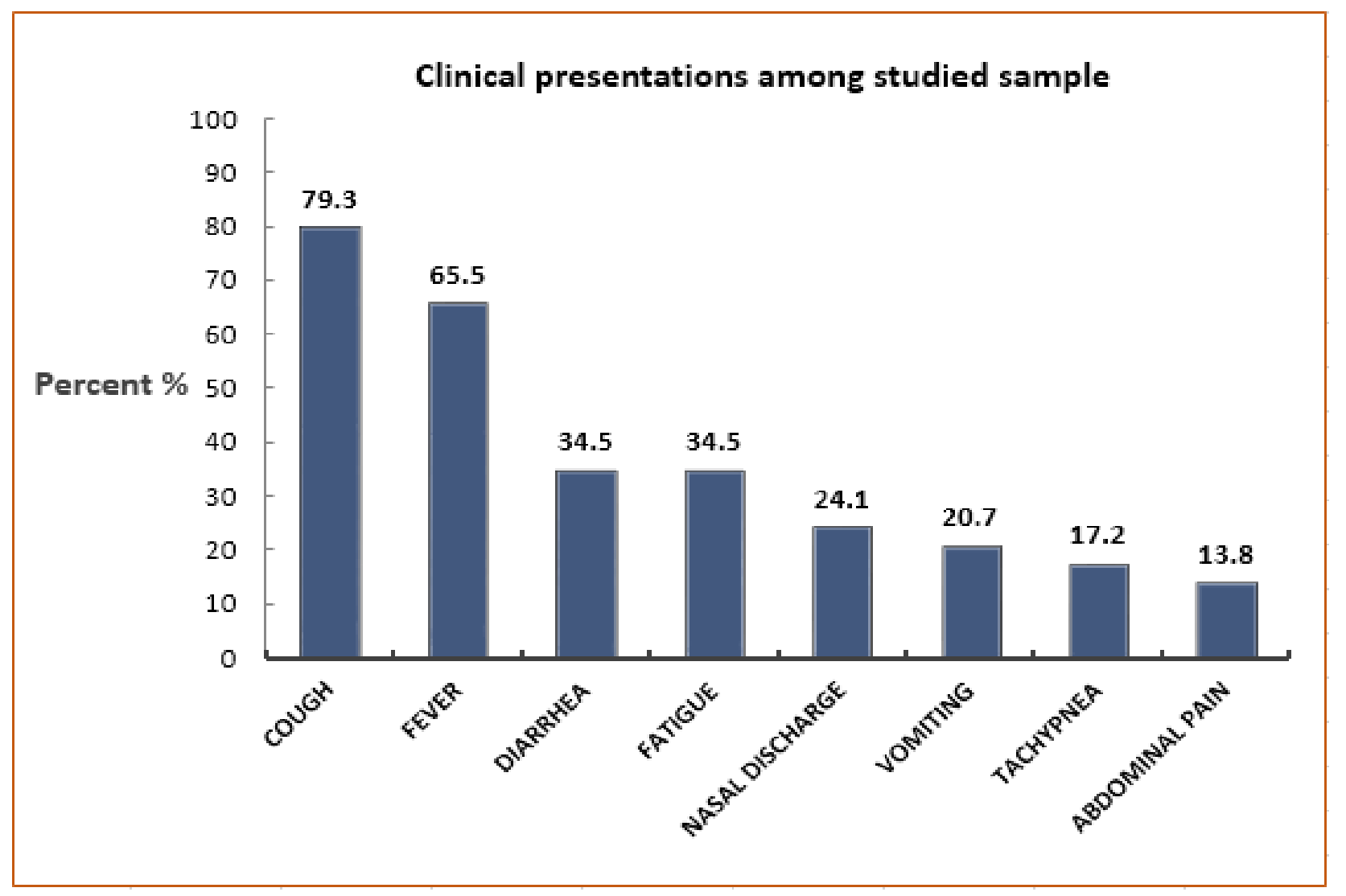

Figure (1): Chart showing clinical presentations among the studied sample.

Comparing the ICU and non ICU patients regarding the clinical presentations (Table 2), revealed that there was a significant association between tachypnea and ICU admission.

Table (2): Clinical presentations of the studied sample.

\begin{tabular}{|c|c|c|c|c|c|c|c|}
\hline \multirow[t]{2}{*}{ Variable } & \multicolumn{2}{|c|}{$\begin{array}{l}\text { Non ICU pediatric } \\
\text { patients }(n=23)\end{array}$} & \multicolumn{2}{|c|}{$\begin{array}{l}\text { ICU pediatric } \\
\text { patients }(n=6)\end{array}$} & \multirow[t]{2}{*}{$P$-value } & \multicolumn{2}{|c|}{$\begin{array}{c}\begin{array}{c}\text { Overall patients } \\
(n=29)\end{array}\end{array}$} \\
\hline & No. & $\%$ & No. & $\%$ & & No. & $\%$ \\
\hline Cough & 19 & $(82.6)$ & 4 & $(66.7)$ & 0.391 & 23 & $(79.3)$ \\
\hline Fever & 13 & $(56.5)$ & 6 & $(100.0)$ & 0.046 & 19 & $(65.5)$ \\
\hline Diarrhea & 7 & $(30.4)$ & 3 & $(50.0)$ & 0.369 & 10 & $(34.5)$ \\
\hline Fatigue & 6 & $(26.1)$ & 4 & $(66.7)$ & 0.062 & 10 & (34.5) \\
\hline Nasal discharge & 7 & $(30.4)$ & 0 & $(0.0)$ & 0.049 & 7 & $(24.1)$ \\
\hline Vomiting & 3 & $(13.0)$ & 3 & $(50.0)$ & 0.046 & 6 & $(20.7)$ \\
\hline Tachypnea & 0 & $(0.0)$ & 5 & $(83.3)$ & $<0.001$ & 5 & $(17.2)$ \\
\hline
\end{tabular}

ICU: intensive care unit

Laboratory findings of the studied patients on admission are shown in table 3. Leukopenia (WBC < age-related reference values) was presented in nine cases. Absolute lymphocytic count decreased than age-related reference range was found in 15 cases.

There were statistically significant differences between the studied groups regarding ALC and platelets count. The frequencies of lymphopenia and thrombocytopenia were higher among ICU patients than the non ICU patients. The ICU patients featured with more profound lymphopenia. The ICU group had significant elevated CRP level. All 29 patients included in our study were discharged after improvement; we did not record any death either in ICU or non ICU patients (Table 3). 
Table (3): Hematological, CRP and CT findings among the studied sample.

\begin{tabular}{|c|c|c|c|c|c|c|c|}
\hline \multirow[t]{2}{*}{ Variable } & \multicolumn{2}{|c|}{$\begin{array}{l}\text { Non ICU pediatric } \\
\text { Patients }(n=23)\end{array}$} & \multicolumn{2}{|c|}{$\begin{array}{l}\text { ICU pediatric } \\
\text { Patients }(n=6)\end{array}$} & \multirow[t]{2}{*}{$\begin{array}{c}P \text { - } \\
\text { value }\end{array}$} & \multicolumn{2}{|c|}{$\begin{array}{c}\text { Overall patients } \\
(\mathrm{n}=29)\end{array}$} \\
\hline & $\begin{array}{l}\text { Median } \\
\text { (IQR) }\end{array}$ & No. (\%) & $\begin{array}{l}\text { Median } \\
\text { (IQR) }\end{array}$ & $\begin{array}{l}\text { No. } \\
(\%)\end{array}$ & & Median (IQR) & No. (\%) \\
\hline Hb $(g / d L)$ & $11.6(10.9-12.2)$ & & $11.1(10.4-12.3)$ & & 0.4 & $11.5(10.9-12.2)$ & \\
\hline WBCs $\left(\times 10^{9} / \mathrm{L}\right)$ & $7.3(3.9-10.3)$ & & $4.3(2.85-6.67)$ & & 0.067 & $6.6(3.65-9.85)$ & \\
\hline Normal & & $16(69.6)$ & & $3(50.0)$ & \multirow{3}{*}{0.493} & & $19(65.5)$ \\
\hline Low & & $6(26.1)$ & & $3(50.0)$ & & & $9(31.0)$ \\
\hline High & \multicolumn{2}{|r|}{$1(4.3)$} & & $0(0.0)$ & & & $1(3.4)$ \\
\hline $\operatorname{ALC}\left(\times 10^{9} / \mathrm{L}\right)$ & $3.43(1.4-4.5)$ & & $1.0(0.77-1.37)$ & & 0.002 & $2.4(1.15-4.15)$ & \\
\hline Normal & \multirow{2}{*}{\multicolumn{2}{|c|}{$\begin{array}{r}14(60.9) \\
0(301)\end{array}$}} & & $0(0.0)$ & \multirow{2}{*}{0.008} & & $14(48.3)$ \\
\hline Low & & & & $6(100)$ & & & $15(51.7)$ \\
\hline $\mathrm{ANC}\left(\times 10^{9} / \mathrm{L}\right)$ & $3.4(2.4-5.5)$ & & $2.3(1.48-4.17)$ & & 0.14 & $3.3(2.25-5.08)$ & \\
\hline Normal > 1.5 & \multicolumn{2}{|r|}{$20(87.0)$} & & $5(83.3)$ & \multirow{2}{*}{0.819} & \multicolumn{2}{|r|}{$25(86.2)$} \\
\hline Low $<1.5$ & \multirow{2}{*}{\multicolumn{2}{|c|}{$1.2(0.78-2.07)$}} & & $1(16.7)$ & & \multicolumn{2}{|r|}{$4(13.8)$} \\
\hline N/L ratio & & & $2.34(1.1-4.0)$ & & 0.1 & $1.2(0.78-2.35)$ & \\
\hline Platelets $\left(\times 10^{9} / \mathrm{L}\right)$ & 255 (194-297) & & $150.5(90-194)$ & & 0.007 & $201(171-290.5)$ & \\
\hline Normal > 150 & \multicolumn{2}{|c|}{$21(91.3)$} & & $3(50.0)$ & \multirow{2}{*}{0.017} & \multicolumn{2}{|r|}{$24(82.2)$} \\
\hline Low $<150$ & \multirow{2}{*}{\multicolumn{2}{|c|}{$2(8.7)$}} & & $3(50.0)$ & & \multicolumn{2}{|r|}{$5(17.2)$} \\
\hline CRP (mg/L) & & & $51(3-70.75)$ & & 0.011 & $3.0(2-21.7)$ & \\
\hline CT findings & & $6(26.1)$ & & $3(50.0)$ & 0.259 & & $9(31.0)$ \\
\hline
\end{tabular}

ALC: absolute lymphocyte count; ANC: absolute neutrophil count; CRP: C-reactive protein; ICU: intensive care unit; IQR: interquartile ranges; N/L: neutrophil/lymphocyte ratio; WBC: white blood cell.

\section{DISCUSSION}

The COVID-19 pandemic has emerged in China; the first cases were reported there in December 2019. As of August 20, 2020, more than 22 million cases of (COVID-19) infection have been reported globally, including more than 780,000 deaths ${ }^{\left({ }^{(9)}\right.}$.

The confrontation of the new pandemic caused by coronavirus disease 2019 (COVID-19) necessitates study and analysis of clinical and laboratory predictors in pediatric population, especially if it is different from adult presentations.

On studying the demographic criteria of our patients, it was noticed that the ages of the patients were of wide range from 45 days to 14 years, so COVID-19 can affect all age groups. The median of ages in ICU group was near that of the non ICU group which suggested that the age didn't affect the severity of disease, which differs from the previous adult study that found that ICU patients were about a decade older than the non-ICU patients ${ }^{(7)}$. This mismatching can be explained by the higher associated co-morbidities with increasing age in adults.

Most of our patients (69\%) acquired COVID19 infection by direct close contact with their family members; our results go with previous study (10). However, another previous study has shown that transmission routes of COVID-19 can be highly variable ${ }^{(11)}$. This situation can be changed with time, when the children return to schools and the disease become more community acquired.

All the patients included in our study were symptomatic, but the majority of them had mild symptoms. However, a previous study showed that one third of children were asymptomatic ${ }^{(10)}$. The clinical presentations of pediatric patients were variable, and it is similar to adults; the most common presentations on admission were cough and fever; going with previous study ${ }^{(12)}$. However, a portion of our studied patients presented with gastrointestinal manifestations like vomiting, diarrhea and abdominal pain.

In our study, most patients had mild disease in contrast to the severe symptoms which reported in adults ${ }^{(3,4)}$. Out of 29 patients, six cases (20.7\%) were admitted to pediatric intensive care unit (PICU), but a previous study showed smaller percent of PICU admission $(8 \%)^{(\mathbf{1 3})}$. This is because we excluded from our study patients with records missing hematology and/or laboratory data and the patients who were transferred to other medical facilities with unknown outcomes. Our percent for ICU admission was less than that of adult; Wang et al. ${ }^{(4)}$ proved that (26\%) of adult patients with confirmed COVID-19 need ICU admission with mortality rate $(4.3 \%)$. None of the patients in our study died, otherwise there was a previous study that recorded $(4.2 \%)$ fatality rate in pediatric patients, this percent represented only two patients who had preexisting co-morbidities ${ }^{(14)}$.

We noticed that only five cases $(17.2 \%)$ presented with tachypnea, nearly matching with other previous study showed that tachypnea affect $(28.7 \%)$ of pediatric patients ${ }^{(15)}$. Notably, all the five cases presented with tachypnea in our study were admitted to ICU. 
In our study there were 15 out of 29 patients $(51.7 \%)$ presented with profound lymphopenia, this number is relatively near previous study done by Zheng et $\boldsymbol{a l}$. $^{(13)}$ and showed that $(40 \%)$ of pediatric patients presented with lymphopenia. Other previous adult study showed that lymphopenia was presented in $(63 \%)$ of patients in Wuhan, China, and $(42 \%)$ of patients outside of Wuhan presented with lymphopenia (16,17).

Notably, in our study, all ICU patients presented with lymphopenia with a median ALC $1 \times 10^{9} / \mathrm{L}$, compared to $3.43 \times 10^{9} / \mathrm{L}$ in non ICU group, however Huang et al. $^{(16)}$ demonstrated that the median for lymphocyte count was $0.4 \times 10^{9} / \mathrm{L}$ and $1 \times 10^{9} / \mathrm{L}$ in ICU and non ICU patients respectively. Their study was on adult patient, which may explain their lower values of lymphocyte count.

In our study, the median for platelet in ICU patients was $150.5 \times 10^{9} / \mathrm{L}$, compared to a relatively high level $255 \times 10^{9} / \mathrm{L}$ in non ICU group. In contrast to other study showed non-significant difference between ICU and non ICU patients ${ }^{(7)}$, their study was done on 58 adult patients.

We noticed high CRP in ICU group compared to non ICU patients. This differs from other study which discussed relation between CRP and severity of COVID-19 and showed that no significant difference between mild and moderate groups as regards CRP level ${ }^{(\mathbf{1 0})}$, that study spared severe and critical cases.

\section{CONCLUSION}

Children are susceptible to COVID-19 infection like adults, but the disease tends to be mild with favorable outcome in children. The common clinical presentations in children are cough and fever. Lymphopenia, thrombocytopenia, and high CRP level can be indicators for the severity and the need for ICU admission.

Funding sources: The authors declare no financial support or interest to this study.

Conflict of interest: The authors declare no conflict of interest.

Availability of data and material: The data that support the findings of this study are available from the corresponding author upon reasonable request.

\section{REFERENCES}

1. Zhu N, Zhang D, Wang W et al. (2020): China novel coronavirus investigating and research team. A novel coronavirus from patients with pneumonia in China, 2019. N Engl J Med., 382(8):727-733.

2. Wei M, Yuan J, Liu Y et al. (2020): Novel coronavirus infection in hospitalized infants under 1 year of age in China. JAMA., 323(13):1313-4.
3. Chen N, Zhou M, Dong $X$ et al. (2020): Epidemiological and clinical characteristics of 99 cases of 2019 novel coronavirus pneumonia in Wuhan, China: a descriptive study. Lancet, 395(10223):507513.

4. Wang D, Hu B, Hu C et al. (2020): Clinical characteristics of 138 hospitalized patients with 2019 novel coronavirus-infected pneumonia in Wuhan, China. JAMA., 323(11):1061-9.

5. Xu Y, Li X, Zhu B et al. (2020): Characteristics of pediatric SARS-CoV-2 infection and potential evidence for persistent fecal viral shedding. Nat Med., 26(4):502-505.

6. She J, Liu L, Liu W (2020): COVID-19 epidemic: Disease characteristics in children. J Med Virol., 92(7):747-754.

7. Fan B, Chong V, Chan S et al. (2020): Hematologic parameters in patients with COVID-19 infection. Am J Hematol., 95(6):E131-E134.

8. Bouffet E, Challinor J, Sullivan M et al. (2020): Early advice on managing children with cancer during the COVID-19 pandemic and a call for sharing experiences. Pediatr Blood Cancer, 67(7):28327-36.

9. World Health Organization (2020): WHO Coronavirus Disease (COVID-19) Dashboard Data .Available at: https://covid19.who.int/.

10. Qiu H, Wu J, Hong $L$ et al. (2020): Clinical and epidemiological features of 36 children with coronavirus disease 2019 (COVID-19) in Zhejiang, China: an observational cohort study. Lancet Infect Dis., 20(6):689-696.

11. Tang B, Bragazzi N, Li Q et al. (2020): An updated estimation of the risk of transmission of the novel coronavirus (2019-nCov). Infect Dis Model, 11(5):248-255.

12. Xia W, Shao J, Guo Y et al. (2020): Clinical and CT features in pediatric patients with COVID-19 infection: Different points from adults. Pediatr Pulmonol., 55(5):1169-1174.

13. Zheng F, Liao C, Fan $Q$ et al. (2020): Clinical characteristics of children with coronavirus disease 2019 in Hubei, China. Curr Med Sci., 40(2):275-280.

14. Shekerdemian L, Mahmood $\mathrm{N}$, Wolfe $\mathrm{K}$ et al. (2020): Characteristics and outcomes of children with coronavirus disease 2019 (covid-19) infection admitted to US and Canadian pediatric Intensive Care Units. JAMA Pediatr., 174(9):868-873.

15. Lu X, Zhang L, Du H et al. (2020): Chinese pediatric novel coronavirus study team. SARS-CoV-2 Infection in Children. N Engl J Med., 382(17):1663-1665.

16. Huang C, Wang $Y$, Li $X$ et al. (2020): Clinical features of patients infected with 2019 novel coronavirus in Wuhan, China. Lancet, 395(10223):497-506.

17. Xu X, Wu X, Jiang $\mathrm{X}$ et al. (2020): Clinical findings in a group of patients infected with the 2019 novel coronavirus (SARS-Cov-2) outside of Wuhan, China: retrospective case series. BMJ., 368:m606. 